\title{
Model-based analysis of sensor faults in SI engine
}

The article focuses on the fault not diagnosed by the OBD system. Apart from mechanical damages sensor faults are a serious group. Although the sensor values are constantly monitored, some errors are not detected. The article presents a diagnostic model of the air intake system of SI engine, which generates the control and work parameters of the engine for fault-free state. The parameters obtained from the reference model can be compared with the parameters measured for the engine in any operating condition. Based on the model the impact of sensor faults for other parameters was analyzed. Some errors can be masked by the adaptive control system of the engine, which changes the parameters of the engine control. Simulation tests were verified on the test bench.

Key words: spark ignition engine, air-intake system, model-based diagnostics, engine sensor faults, residuals

\section{Introduction}

Traditional diagnostic systems compare the measurement results with fixed limits. If the sensor signal voltage does not exceed the limit values, then the measurement is acceptable. Meanwhile, with the time the characteristics of the sensors are changed, leaks appear in the intake manifold, contacts become dirty and wet. It can change the indications of sensors, but signal voltage still does not reach the limits [8]. Adaptive control system of the engine will adjust the fuel dose - based on the lambda sensor indications - to new conditions. That is good, because the driver with any malfunction does not have to follow the service. Sometimes, however, the driver feels something is wrong with the engine, but the error is not detected [2, 3, 5, 13].

Another, also traditional approach to diagnosing, is hardware redundancy or multiplication of sensors. However, this is a costly solution, takes place and additionally weighs. Double potentiometric sensors are used for example in the gas pedal and throttle of engine.

Modern diagnostic systems [14, 15] use mathematical models to estimate measured physical quantities. These models act as virtual sensors. Based on the indications of other sensors recognised as efficient and relations of mathematical or statistical models, the rational indications investigated sensors are estimated and compared with an indication of the physical sensors $[4,10,16,17]$. Virtual sensors can be divided into static - model-based, or dynamic using observers $[1,18,19]$. This article defines virtual sensors in the air intake system.

\section{Mean-value model of the air intake system}

The state of the cylinder is defined by the mass and the internal energy of air contained in the cylinder. Fig. 1 shows a cross-section of the intake manifold. The throttle angle $\alpha$ controls the flow of air mass into the manifold.

The adiabatic flow across the throttle body/butterfly valve can be modeled as air flow from orifice. While modeling it is assumed that one-dimensional compressible flow has no friction and inertial effects in the flow and there is no change in temperature and pressure (lumped parameter approach) during the flow $[6,7,9,11]$.

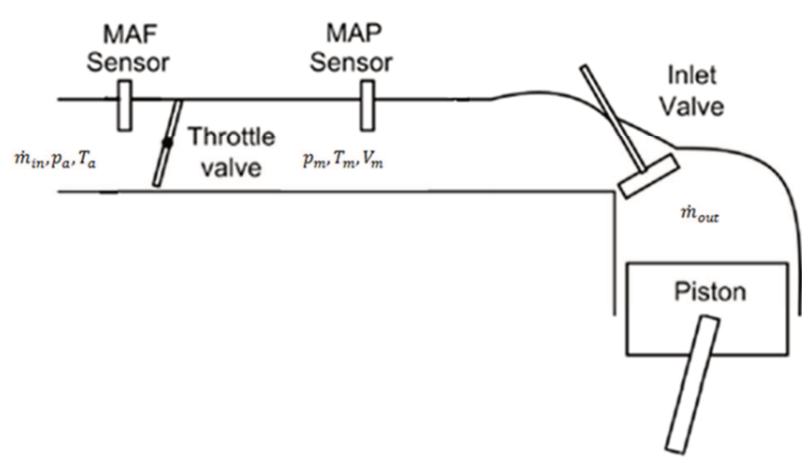

Fig. 1. Air intake system

Moreover, the fuel and temperature dynamics involved in air intake system are assumed to be uniform. The mass and energy of the air serves as inputs and outputs of the receivers. It is also assumed that no substantial changes occur in energy and no mass \& heat transfers through the manifold walls. The manifold pressure dynamics can be modeled on the basis of filling and emptying of air behaving as perfect gas as shown in (1)

$$
\mathrm{p}_{\mathrm{m}}(\mathrm{t})=\frac{\mathrm{RT}_{\mathrm{m}}}{\mathrm{V}_{\mathrm{m}}}\left(\mathrm{m}_{\text {in }}(\mathrm{t})-\mathrm{m}_{\text {out }}(\mathrm{t})\right)
$$

where: $\mathrm{p}_{\mathrm{m}}$ - change of manifold pressure, $\mathrm{T}_{\mathrm{m}}-$ manifold temperature, $\mathrm{V}_{\mathrm{m}}$ - manifold volume, $\mathrm{R}$ - specific gas constant, $\dot{m}_{\text {in }}$ - air mass flow into the manifold, $\dot{m}_{\text {out }}-$ air mass flow out from the manifold.

The manifold absolute pressure sensor provides instantaneous manifold pressure information to the electronic control unit of engine. A fuel-injected engine may alternatively use a mass airflow sensor to find out the mass flow rate of air entering a fuel-injected internal combustion engine. The air mass information is necessary for the engine control unit to balance and deliver the correct fuel mass to the engine.

Air mass flow into the manifold is described as a function:

$$
\dot{\mathrm{m}}_{\mathrm{in}}(\mathrm{t})=\mathrm{f}\left(\mathrm{p}_{\mathrm{m}}, \alpha\right)
$$


where $\mathrm{p}_{\mathrm{m}}$ - manifold pressure, $\alpha$ - throttle angle, and air mass flow out from the manifold as a function:

$$
\dot{\mathrm{m}}_{\mathrm{in}}(\mathrm{t})=\mathrm{f}\left(\mathrm{p}_{\mathrm{m}}, \mathrm{n}\right)
$$

where $\mathrm{n}$ - engine speed.

At stationary engine operation it can be assumed that

$$
\dot{\mathrm{m}}_{\mathrm{in}}(\mathrm{t})=\dot{\mathrm{m}}_{\text {out }}(\mathrm{t})=\dot{\mathrm{m}}_{\mathrm{a}}(\mathrm{t})
$$

where $\dot{m}_{\mathrm{a}}$ - air mass flow rate measured with air flowmeter.

At stationary engine operation one of the engine load measure: throttle angle $\alpha$, air flow $\mathrm{m}_{\mathrm{a}}$, manifold pressure $\mathrm{p}_{\mathrm{m}}$, can be estimated from the remaining measurements and the rotational engine speed $\mathrm{n}$ [12].

The simple diagnostic model is presented in Fig. 2. Model was implemented in Matlab Simulink.

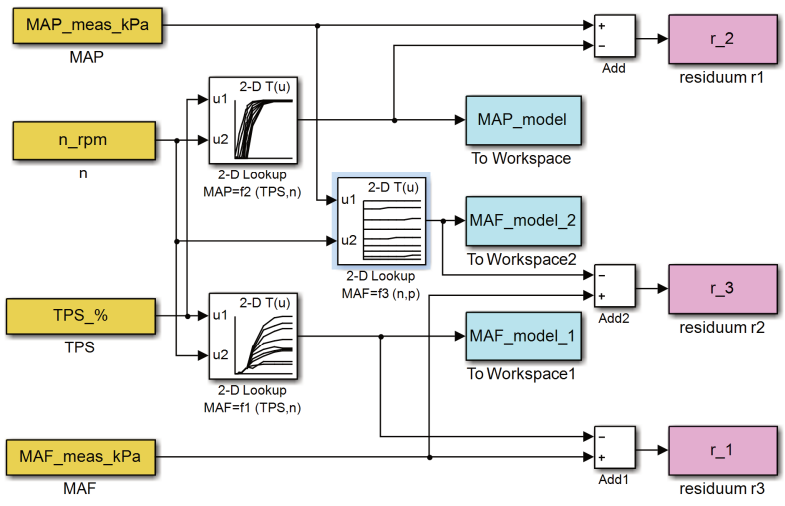

Fig. 2. Diagnostic model of air intake system

The inputs of the model are averaged values of signals: throttle position $\alpha$, engine rotational speed $\mathrm{n}$, manifold pressure $\mathrm{p}_{\mathrm{m}}$ and air mass flow $\mathrm{m}_{\mathrm{a}}$. In the model three lookup tables, that were taken in empirical way, were used:

$$
\begin{gathered}
\dot{\mathrm{m}}_{\mathrm{a}}=\mathrm{f}_{1}(\alpha, \mathrm{n}) \\
\mathrm{p}_{\mathrm{m}}=\mathrm{f}_{2}(\alpha, \mathrm{n}) \\
\dot{\mathrm{m}}_{\mathrm{a}}=\mathrm{f}_{3}\left(\mathrm{n}, \mathrm{p}_{\mathrm{m}}\right)
\end{gathered}
$$

During simulations with the model for steady state, following residuals are generated:

$$
\begin{gathered}
\mathrm{r}_{1}=\mathrm{m}_{\mathrm{a}}-\mathrm{f}_{1}(\alpha, \mathrm{n}) \\
\mathrm{r}_{2}=\mathrm{p}_{\mathrm{m}}-\mathrm{f}_{2}(\alpha, \mathrm{n}) \\
\mathrm{r}_{3}=\dot{\mathrm{m}}_{\mathrm{a}}-\mathrm{f}_{3}\left(\mathrm{n}, \mathrm{p}_{\mathrm{m}}\right)
\end{gathered}
$$

The i-th residual indicator $R$ is established in the following way:

$$
R_{i}=\left\{\begin{array}{lll}
0 & \text { if } & r_{i} \leq u \\
1 & \text { if } & r_{i}>u
\end{array}\right.
$$

where $u$ is the model uncertainty.
The components of the model uncertainty are: measurement errors, uniqueness of working cycles of engine and model interpolation errors.

Based on the defined functions, three sensor faults (throttle angle sensor, air mass flowmeter, manifold pressure sensor or manifold leakage) can be detected. The engine speed sensor is not diagnosed, because it is monitored in other systems e.g. in the ABS system.

\section{Model identification}

To find the functions described in (5-7), a steady state experiment was performed. Investigations were conducted on the passenger car Mitsubishi Carisma with four-cylinder spark ignition engine of a gasoline direct injection (GDI) [20]. The solutions applied in this vehicle such as a design and engine equipment are commonly used in the automotive market. This substantiates the assumption as to the universality of the conclusions and trends resulting from the investigations. The car was positioned on a chassis dynamometer. It is possible to brake a vehicle with the given moment on wheels, or accelerated to the given speed. In such way the vehicle engine was loaded to the required and simultaneously constant speed $n$ at various throttle openings $\alpha$.

Tests were based on recording signals in 10-seconds stretches from selected sensors of the engine at stationery operation. Recording was performed by the computer system of collecting data consisted of the computer with the measuring equipment OCTOPUS CompuScope 8380 of the GAGE Company. This device allows sampling of all signals with a frequency from $1 \mathrm{kHz}$ to $10 \mathrm{MHz}$ and the resolution of 14 bits. The following voltage signals were recorded:

- crankshaft position sensor

- camshaft position sensor

- mass airflow (MAF) sensor

- throttle valve position (TPS) sensor

- manifold absolute pressure (MAP) sensor - an additional sensor not used as a standard in this car

- output signal of the analyser of the composition of combusted mixture, MEXA700 $\lambda$ of the HORIBA Company In addition, temperatures of the liquid cooling the engine and of the sucked-in air were recorded, for each stationary engine operation point.

Tests were carried out for 9 equally spaced engine speeds (1000 to $5000 \mathrm{rpm})$ and throttle positions: $6-26 \%$ (without load), 34\%, 53\%, 70\%, 83-87\%, 90-100\%. The throttle angle was expressed in percentages, where 0 means the total closing and $100 \%$ the total opening of the throttle. Since signals were recorded in steady states the average values of the above signals were determined for each second of the recording, it means 10 values for the given point $(\mathrm{n}, \alpha)$.

The surfaces described by equation (5-7) are presented in Fig. 3, together with the marked measuring points.

To represent the functions $\mathrm{f}_{1}, \mathrm{f}_{2}$ and $\mathrm{f}_{3}$, the interpolation in the maps or polynomial equations can be used. The identification quality of models was characterised by root mean squared errors. 
a)

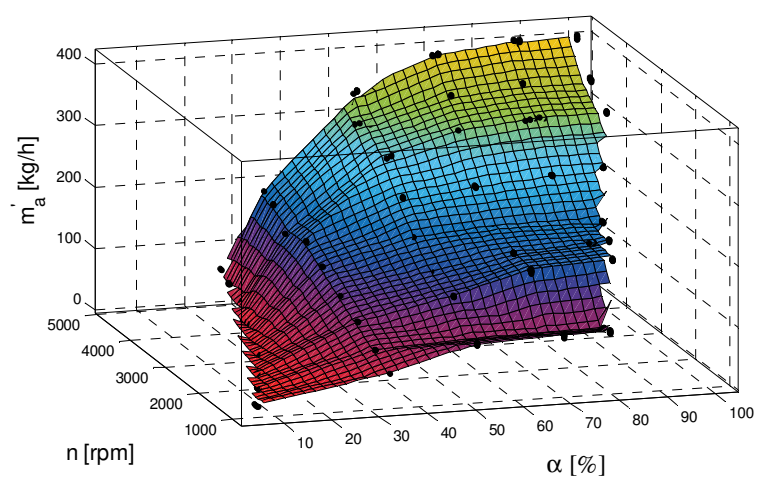

b)

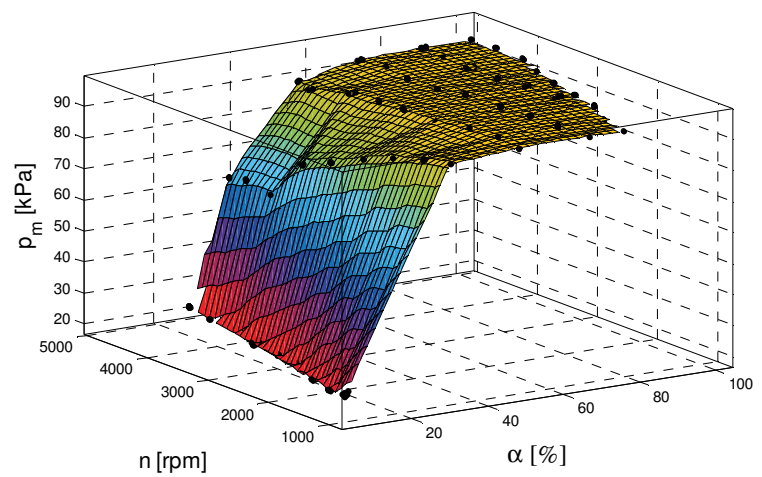

c)

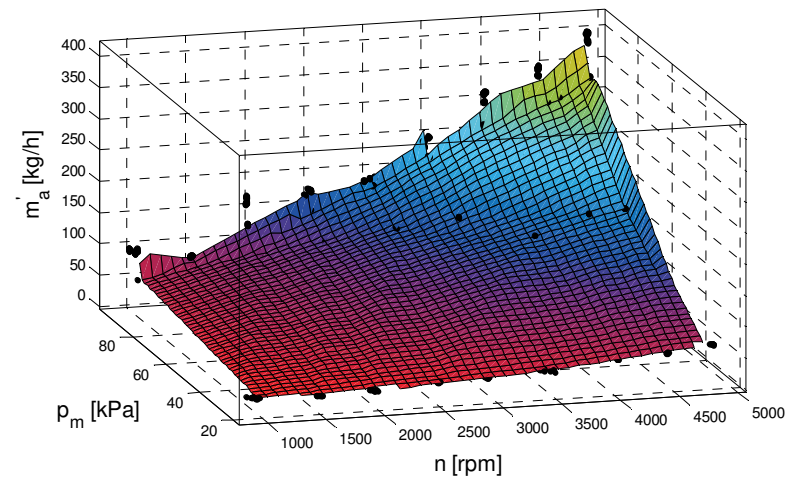

Fig. 3. Functions used in diagnostic model

\section{Model validation}

To validate the model, measurements and calculation procedures were repeated for three simulated faults:

1. Air mass flowmeter fault caused by chocking the part of the flow channel, from the air filter side.

2. Throttle angle sensor fault caused by characteristic change that occurring e.g. in a situation of wetting the electrical installation or sensor flooding.

3. Manifold air leakage.

In all these situations the on-board diagnostics (OBD) system did not record an error, while the user could notice the change in the engine operation in a form of roughness or a power loss at higher rotational speeds of the engine.

The throttle position sensor, the mass air flow sensor and the rotational speed sensor are installed as a standard in the tested engine. Whereas the manifold absolute pressure sensor was installed additionally in the intake manifold for diagnostics aims.

\subsection{Fault of air mass flowmeter}

Partial obscuration of the intake manifold has caused flow disturbances and malfunction of the Karman vortex air mass flowmeter. Large fluctuations in air mass index caused a oscillations in fuel dose and consequently uneven working of the engine. Consequently, this resulted in uneven rotational speed and variations in mixturecomposition (Fig. 4).
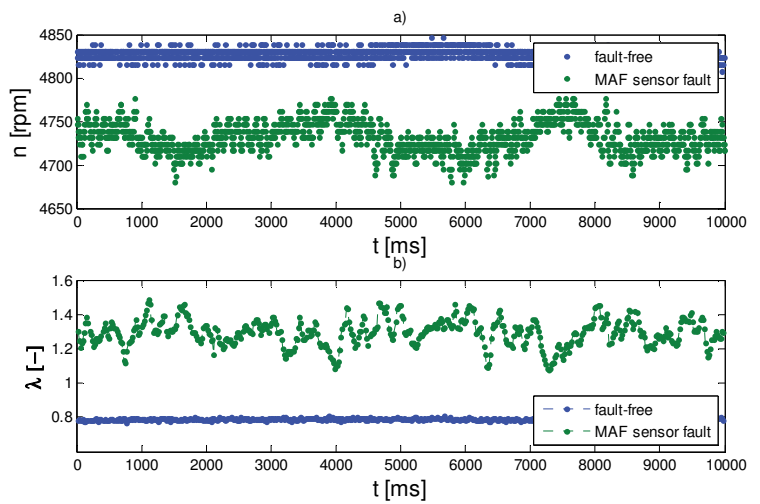

Fig. 4. Instantaneous values of a) engine speed and b) lambda coefficient, for fault-free and MAF sensor fault states at $85 \%$ throttle opening and $4800 \mathrm{rpm}$

The indicated flow is so small that the engine changes into supplying by a very lean mixture (recorded air-fuel ratio $\lambda>1$ ). The adaptive control system will try to adjust the fuel dose based on the lambda sensor indication. Average air mass flow rate values are lower than at fault-free operation.

Fig. 5 shows the results of the measurements of intake manifold pressure and the mass air flow for the described failure at $85 \%$ of the throttle opening.
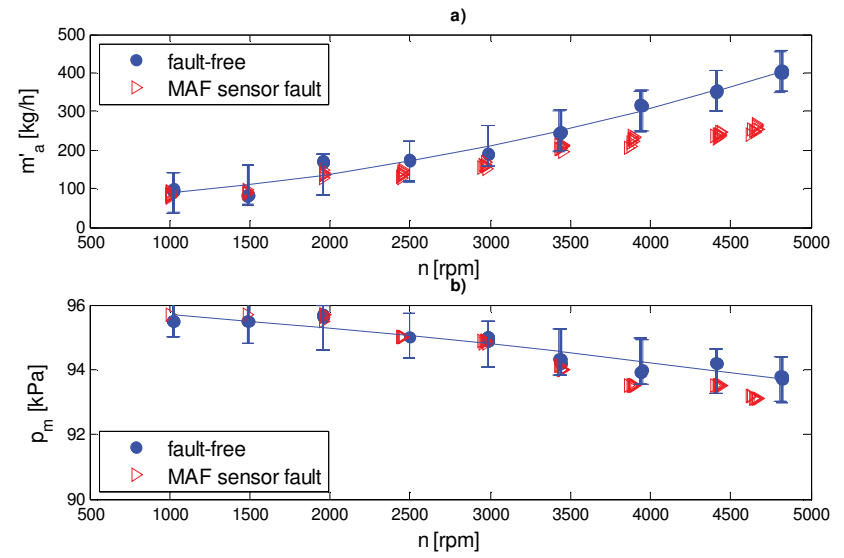

Fig. 5. Comparison of sensors indications for two states: fault-free and MAF sensor fault at throttle opening $85 \%$ a) MAF sensor, b) MAP sensor

Pressure in the intake manifold is within error limits of the model, while the mass air flow is lower than it results from the model for the whole range of engine loads. 


\subsection{Fault of throttle position sensor}

In the second case - characteristic changes of the throttle angle sensor (Fig. 6) - the fault was simulated by bypassing the output of the second throttle channel with the resistor of $5.57 \mathrm{k} \Omega$. This can correspond to the situation when the sensor is flooded or electrical installation wetted. A careful car user feels it as a small power decrease of the engine.

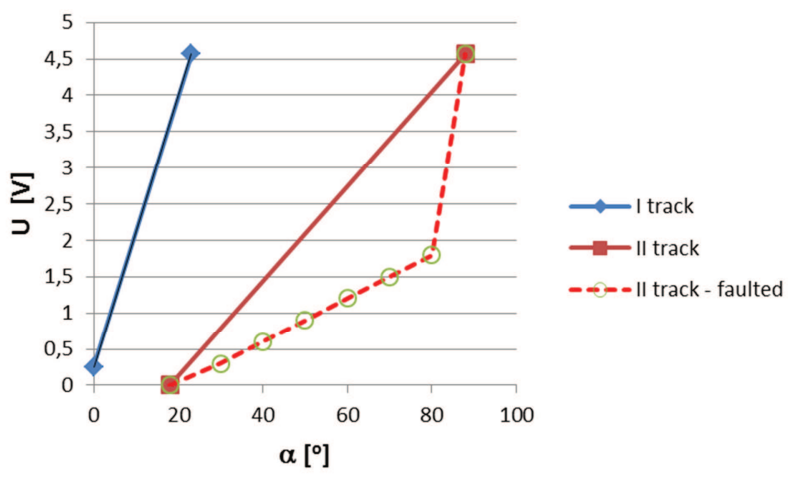

Fig. 6. Change of TPS characteristics caused by fault

Fig. 7 shows the results of measurements of the intake manifold pressure and the mass air flow for the described failure at $50 \%$ of the throttle opening. In this case, in a range of medium loads and high rotational speeds $(n>4000$ $\mathrm{rpm}$ ), a significant increase of signal indications from the pressure sensor as compared with the model sensor is observed, as well as a decrease of the mass air flow sensor indications as compared with the model.
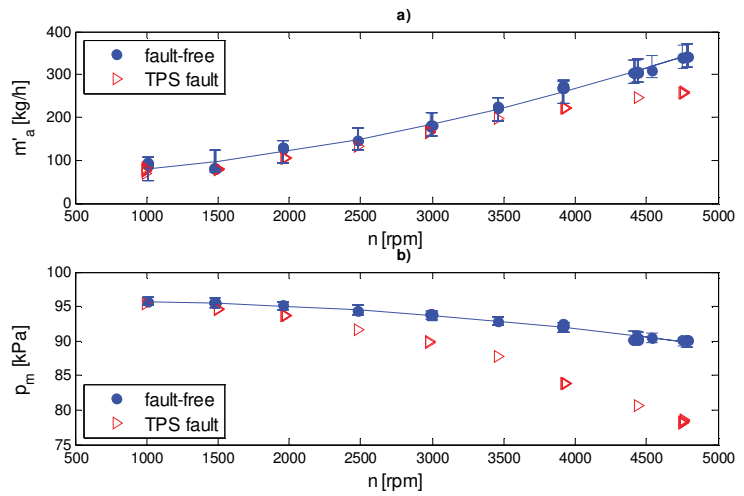

Fig. 7. Comparison of sensors indications for two states: fault-free and throttle position sensor fault at throttle opening 50\% a) MAF sensor, b) MAP sensor

\subsection{Leakage of the intake manifold}

The third case constitutes air leakage of the intake manifold, which can cause such effects as: hissing noise, engine stumbling, rough or fast idling or stalling, poor gas mileage. Tests were performed at the small leakage, at which the onboard diagnostics system did not record any error. The mass air flow indicated the correct value, while the pressure sensor indicated underrated value as compared with the corresponding model, especially in the range of high loads.

Fig. 8 shows the results of measurements of the intake manifold pressure and the mass air flow for the described failure at $85 \%$ of the throttle opening.
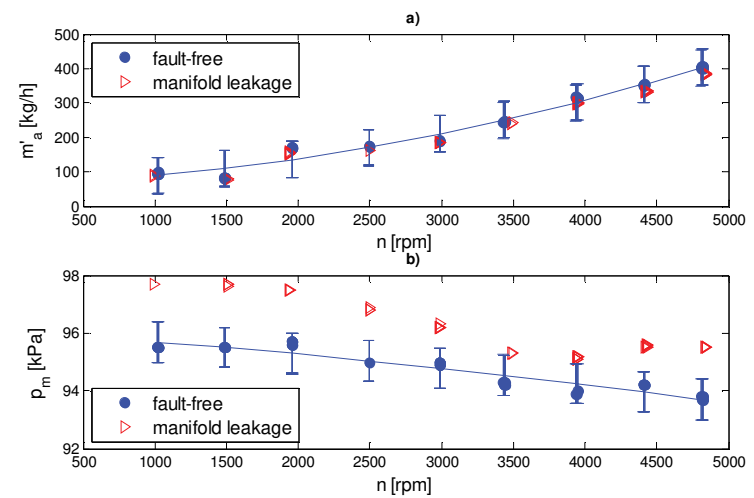

Fig. 8. Comparison of sensors indications for two states: fault-free and manifold leakage at throttle opening $85 \%$ a) MAF sensor, b) MAP sensor

The manifold pressure signal values in this case are larger than in fault-free state for all engine speeds, while the air mass values remain the similar. The fuel injection control of the tested engine is based on indications of MAF sensor. In this case the adaptive control system will try to adjust the fuel dose based on the lambda sensor indication.

\subsection{Residuals analysis}

During simulation of the model three residuals $r_{1}, r_{2}, r_{3}$, described with equations (8-10) are generated. It can be created multiple residuals, but in this simple example they do not provide any new information.

Residuals should be generated for several operation points at stationary condition. Fig. 9 shows the relationship between three indications describing the engine load: throttle position $\alpha$, manifold pressure $\mathrm{p}_{\mathrm{m}}$ and air mass flow rate $\dot{m}_{a}$ for engine speed $\mathrm{n}=4500 \mathrm{rpm}$.
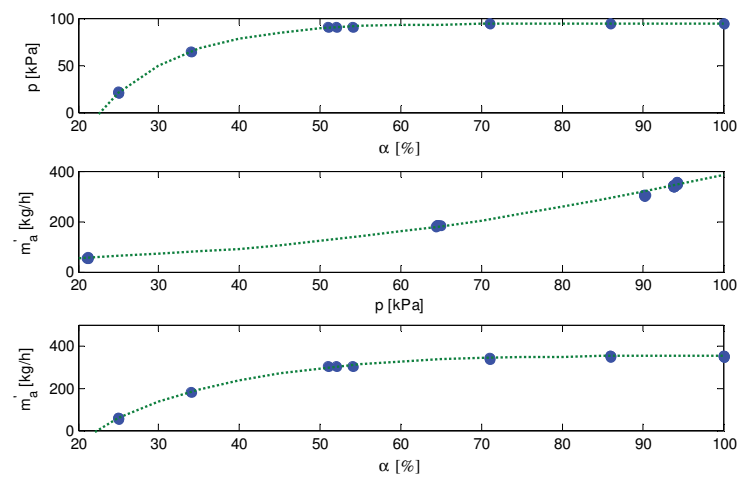

Fig. 9. Relationship between throttle position, manifold pressure and mass air flow for GDI engine at engine speed $n=4500 \mathrm{rpm}$

The simulation was performed for four states: fault-free, MAF sensor fault (fault 1), TPS sensor fault (fault 2), manifold air leakage (fault 3). It was assumed that only one fault can occur at the same time. For one selected engine operating point ( $\mathrm{n}=4500 \mathrm{rpm}, \alpha=85 \%)$, the simulated results with measurements were compared (Fig. 10). Averaged values of manifold pressure signal and air mass flow rate signal were compared with the outputs of the model i.e. functions $f_{1}, f_{2}, f_{3}$ described in the equations (5-7). 

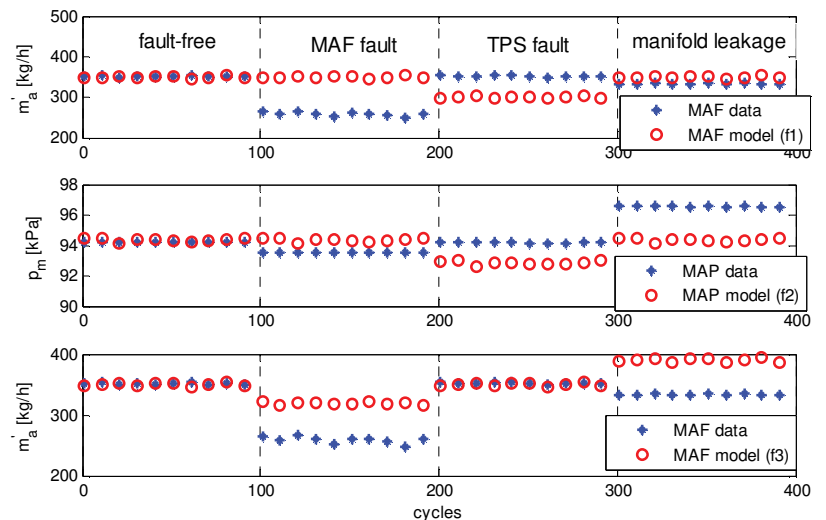

Fig. 10. Comparison of results of model simulation and measured data for four states of air intake system at $85 \%$ opening position of throttle valve and engine speed $4500 \mathrm{rpm}$

The residuals described in the formulas (8-10) were calculated and residual indicators described in formula (11) were summarised in Table 1 .

Table 1. Residual indicators

\begin{tabular}{|l|c|c|c|c|}
\hline & \multicolumn{4}{|c|}{$\mathrm{n}=4500 \mathrm{rpm}, \alpha=85 \%$} \\
\hline Parameter & fault-free & MAF fault & TPS fault & $\begin{array}{c}\text { manifold } \\
\text { leakage }\end{array}$ \\
\hline R1 & 0 & 1 & 1 & 0 \\
\hline R2 & 0 & 0 & 1 & 1 \\
\hline R3 & 0 & 1 & 0 & 1 \\
\hline
\end{tabular}

The residuals takes two states: 1 means that the difference between data end model output surpasses the value of model uncertainty and 0 means that the difference lies within the limits of model error. In the simple case only three residuals are sufficient.

\section{Conclusions}

The article proposes the model-based method of diagnosing faults in the air-intake control system of engine not diagnosed by Mitsubishi Carisma OBD system. Incorrect measurement of airflow, change of throttle position sensor characteristics and leakage in intake manifold were tested. Based on simulation, residuals were generated.

The diagnostic method described here is based on measurements of all three physical quantities, which are a measure of the load on the engine: mass air flow, manifold pressure and throttle angle.

However, only two sensors are commonly installed in cars. In Mitsubishi throttle angle and mass air flow are measured. Based on measurements from two sensors, function $f_{3}$ cannot be determined. However, the TPS sensor error can be ruled out by comparing its indication with the second redundant TPS sensor.

This method has been verified for steady-state operation of the engine and illustrated for one operating point of engine. The residuals generation should be repeated for several steady-state operation condition (different rotational speeds and loads), as errors are not always reflected in measurements. Defect can be detected if the corresponding residuum is greater than the uncertainty of the model.

\section{Nomenclature}

SI spark ignition

GDI gasoline direct injection

MAP manifold absolute pressure

MAF mass air flow

TPS throttle position sensor

ABS anti-lock breaking system
OBD on-board diagnostics

$\alpha \quad$ throttle position

$\mathrm{n} \quad$ rotational speed of engine

$\mathrm{p}_{\mathrm{m}} \quad$ manifold pressure

$\mathrm{m}_{\mathrm{a}} \quad$ air mass flow rate

\section{Bibliography}

[1] AHMED, Q., BHATTI, AI., KHAN, Q., RAZA, M. Condition monitoring of gasoline engine air intake system using second order sliding modes. International Journal of Vehicle Design. 2013, 62(2-4), 312-332.

[2] DĄBROWSKI, Z., MADEJ, H. Masking mechanical damages in the modern control systems of combustion engines. Journal of Kones Powertrain and Transport. 2006, 13(3), 53-60.

[3] DĄBROWSKI, Z., ZAWISZA, M. Investigations of the vibroacoustic signals sensitivity to mechanical defects not recognised by the OBD system in diesel engines. Mechatronic Systems, Mechanics and Materials. Solid State Phenomena. 2012, 180, 194-199.

[4] DUTKA, A., JAVAHERIAN, H., GRIMBLE, M. Modelbased engine fault detection and isolation. Proceedings of American Control Conference. ACC '09. 2009, 4593-4600.

[5] FIGLUS, T., KONIECZNY, Ł., BURDZIK, R., CZECH, P. Assessment of diagnostic usefulness of vibration of the common rail system in the diesel engine. Vibroengineering PROCEEDIA. 2015, 6, 185-189.

[6] FRANCHEK, M.A., BUEHLER, P.J., MAKKI, I. Intake air path diagnostics for internal combustion engines. Journal of Dynamic Systems, Measurement and Control. 2007, 129(1), 32-40.

[7] GUZZELLA, L., ONDER, C. Introduction to modeling and control of internal combustion engine systems. Springer, ETH Zurich 2004.

[8] HERNER, A., RIEHL, H.J. Elektrotechnika i elektronika w pojazdach samochodowych. WKiE, Warszawa 2013.

[9] HEYWOOD, J.B. Internal Combustion Engine Fundamentals. Mc-Graw Hill, New York 1988.

[10] ISERMANN, R. Model-based fault-detection and diagnosis - status and applications. Annual Reviews in Control. 2005, 29, 71-85.

[11] JONGENEEL,J., NIJMEIJER, H., MANZIE, C., NESIC, D. Input redundant internal combustion engine with linear quadratic Gaussian control and dynamic control allocation. 
Internal Report. Eindhoven University of Technology, Eindhoven, Netherlands 2009.

[12] KIENCKE, U., NIELSEN, L. Automotive control systems. For engine, driveline, and vehicle. Springer-Verlag, Berlin Heidelberg 2005.

[13] KOMORSKA, I., PUCHALSKI, A. On-board diagnostics of mechanical defects of the vehicle drive system based on the vibration signal reference model. Journal of Vibroengineering. 2013, 15(1), 450-458.

[14] MERKISZ, J., MAZUREK S. Pokładowe systemy diagnostyczne pojazdów samochodowych. WKiE, Warszawa 2006.

[15] MERKISZ, J., PIELECHA, J., RADZIMIRSKI, S. New trends in emission control in the European Union. Springer 2014.

[16] NYBERG, M., NIELSEN, L. Model based diagnosis for the air intake system of the SI-engine. SAE Technical Paper. 1997, 970209.

Iwona Komorska, DSc., DEng. - Faculty of Mechanical Engineering at University of Technology and Humanities in Radom.

e-mail: Iwona.Komorska@uthrad.pl
Zbigniew Wołczyński, DEng. - Faculty of Mechanical Engineering at University of Technology and Humanities in Radom.

e-mail: Z.Wolczynski@uthrad.pl

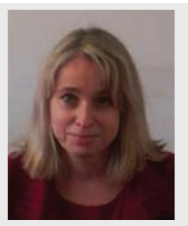

Artur Borczuch, MEng. - Faculty of Mechanical Engineering at University of Technology and $\mathrm{Hu}-$ manities in Radom.

e-mail: A.Borczuch@uthrad.pl

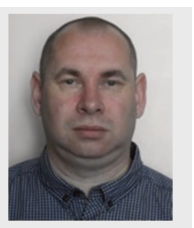

[17] NYBERG, M. Model-based diagnosis of an automotive engine using several types of fault models. IEEE Transactions on Control Systems Technology. 2002, 10(5), 679-689.

[18] PUCHALSKI, A., KOMORSKA I. Online fault diagnosis of automotive powernets by kalman filtering. Key Engineering Materials. 2014, 588, 209-213.

[19] WENZEL. T.A., BURNHAM, K.J., BLUNDELL, M.V. Kalman filter as a virtual sensor: applied to automotive stability systems. Transactions of the Institute of Measurement and Control. 2007, 29(2), 95-115.

[20] WOŁCZYŃSKI, Z., KOMORSKA, I., BORCZUCH A. Wpływ uszkodzeń w układzie dolotowym powietrza na sterowanie silnikiem spalinowym. Autobusy - Technika, Eksploatacja, Systemy transportowe. 2016, 17(12), 1487-1490.

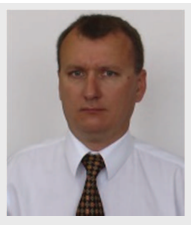

